\title{
LL37 peptide@silver nanoparticles: combining the best of the two worlds for skin infection control
}

\author{
Mariana Vignoni, Hasitha de Alwis Weerasekera, Madeline J. Simpson, Jaywant Phopase, \\ Thien-Fah Mah, May Griffith, Emilio I. Alarcon and Juan Scaiano
}

\section{Linköping University Post Print}

\section{Tweet}

N.B.: When citing this work, cite the original article.

Original Publication:

Mariana Vignoni, Hasitha de Alwis Weerasekera, Madeline J. Simpson, Jaywant Phopase, Thien-Fah Mah, May Griffith, Emilio I. Alarcon and Juan Scaiano, LL37 peptide@silver nanoparticles: combining the best of the two worlds for skin infection control, 2014, Nanoscale, (6), 11, 5725-5728.

http://dx.doi.org/10.1039/c4nr01284d

Copyright: Royal Society of Chemistry http://www.rsc.org/

Postprint available at: Linköping University Electronic Press http://urn.kb.se/resolve?urn=urn:nbn:se:liu:diva-108794 


\title{
LL37 peptide@silver nanoparticles: Combining the best of the two worlds for skin infection control
}

\author{
Mariana Vignoni, ${ }^{a, \#}$ Hasitha de Alwis Weerasekera, ${ }^{a}$ Madeline J. Simpson, ${ }^{a}$ Jaywant Phopase, \\ ${ }^{b}$ Thien-Fah Mah, ${ }^{\mathrm{c}}$ May Griffith, ${ }^{* b}$ Emilio I. Alarcon*a and Juan C. Scaiano ${ }^{* a, b}$ \\ ${ }^{a}$ Department of Chemistry and Centre for Catalysis Research and Innovation, University of Ottawa, Ottawa, \\ Ontario, K1N $6 \mathrm{N5}$ \\ ${ }^{b}$ Integrative Regenerative Medicine Centre, Departments of Clinical and Experimental Medicine and \\ Physics, Chemistry and Biology, Linköping University, S-58185 Linköping, Sweden \\ ${ }^{c}$ Department of Biochemistry, Microbiology and Immunology \\ Faculty of Medicine, University of Ottawa, Ottawa, Ontario, K1H 8 M5 \\ \# On leave from: Dep. de Química, Facultad de Ciencias. Exactas, Instituto de Investigaciones \\ Fisicoquímicas Teóricas y Aplicadas, Universidad Nacional de La Plata, CCT La Plata-CONICET, La Plata, \\ Argentina \\ *Corresponding author: scaiano@photo.chem.uottawa.ca; emilio@photo.chem.uottawa.ca; \\ may.griffith@liu.se
}

\section{Summary}

Capping silver nanoparticles with LL37 peptide eradicates the antiproliferative effect of silver on primary skin cells, but retains the bactericidal properties of silver nanoparticles with activities comparable to silver nitrate or silver sulfadiazine. In addition, LL37 capped silver nanoparticles have anti-biofilm formation activity.

\section{Main text}

The human skin is both a physical and immune barrier that protects against colonization by microorganisms. Its many cell types include cells that provide pathogen recognition and defence to production of innate anti-microbial peptides.[1] In burn patients, particularly deeper burns, the barrier integrity is compromised and hence, nosocomial bacterial infections are a major problem in the management of patients in burn care centres.[2] Pseudomonas aeruginosa ( $P$. aeruginosa), a Gram negative microbe, in particular, is responsible for much of the recurrent opportunistic bacterial infections, mainly because of biofilm formation.[2] Other bacteria that contribute to problematic nosocomial infections include Gram positive bacteria, Staphylococcus epidermidis (S. epidermidis) and aureus (S. aureus), and Gram negative, Escherichia coli (E. coli). [2]

The keratinocytes of the healthy skin produce innate anti-microbial peptides such as the cathelicidin LL37 and defensins.[1] The LL37 peptide displays antimicrobial activity and has a direct effect in wound healing, neovascularization and angiogenesis.[3] This peptide has been tested as a potential alternative to antibiotics for treatment of ulcerative wounds and shows good potential.[4] In the clinic, combinatory use of ionic silver and antibiotics has been proposed as a new strategy to minimize antibiotic resistance.[5] However, the main shortcoming of using ionic silver, $\mathrm{Ag}^{+}$, is that it relies upon the anti-proliferative effect that silver has on primary cells.[2, 6, 7] In burn patients, cell proliferation to repair 
the wound site is as badly needed as the infection control itself. We have, however, shown that silver nanoparticles (AgNP) that are stabilized with collagen are cell-friendly for primary skin cells and yet demonstrate bacteriocidal and bacteriostatic effects. [7] Recent work by Herzog et al., has also demonstrated the biocompatibility of silver nanoparticles with airway epithelial cells.[8]

In this study, we tested the combination of AgNP with CSG -LL37 peptide, where the -SH served as stabilizer on the AgNP surface [9] forming LL37@AgNP as a new antimicrobial and anti-biofilm agent. Details of the LL37 synthesis are in SI. Note that the antimicrobial activity, against $P$. aeruginosa, and conformation of LL37 peptide is preserved in truncated peptides containing only the sequence LL7-37 (or RK-31). [10]

The photochemical preparation of biocompatible, protected silver nanoparticles (AgNP) has been previously reported by our group using a variety of biomolecules including type I collagen, human serum albumin, and poly-L-lysine.[11-13] However, the photochemical synthesis of peptide capped AgNP remained, however, unexplored. Upon 0.5 min of UVA exposure of oxygen-free aqueous solutions containing AgNO3, I-2959 and micromolar concentrations of LL37 peptide, the formation of an absorption band around $400 \mathrm{~nm}$ was observed (Fig. 1A) whose intensity gradually increased up to minute three, where it reaches a plateau. This is most probably due complete reduction of $\mathrm{Ag}^{+}$by I-2959 ketyl radical (Fig. S1).
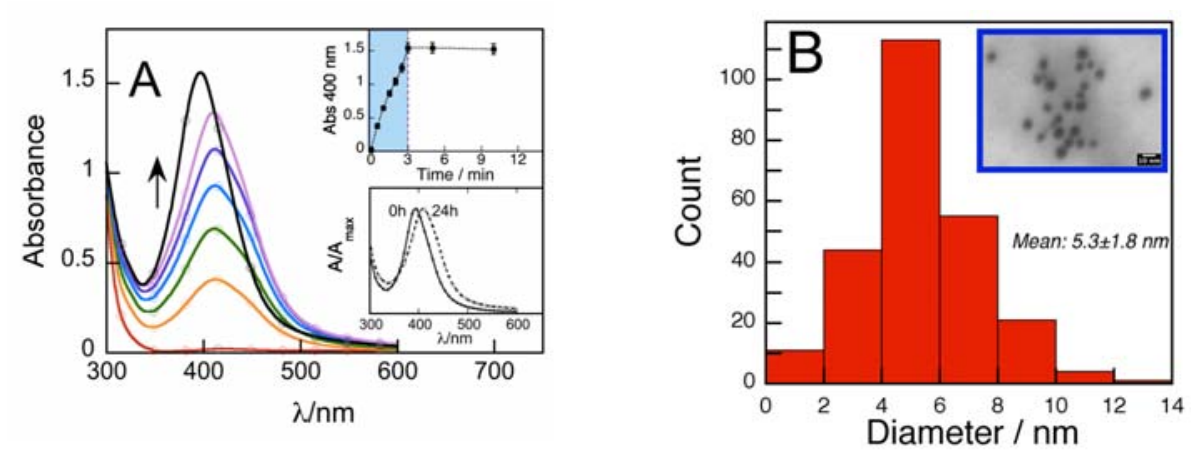

Figure 1. (A) Photochemical formation of LL37@AgNP upon UVA exposure of a oxygen free solution containing 0.2 $\mathrm{mM} \mathrm{AgNO}, 0.2 \mathrm{mM} \mathrm{I-2959}$ and $2.5 \mu \mathrm{M}$ LL37. Absorption spectra taken at different times as indicated in the figure. Top inset: Changes on the absorption at $400 \mathrm{~nm}$ vs. irradiation time. Bottom inset: Absorption spectra for LL37@AgNP time 0 after synthesis and 24 h elapsed (B) Size histogram and TEM image (inset) for a selected area of LL37@AgNP. Average size calculated from 400 individual particles. The blurriness observed in the image corresponds to organic material (most likely the LL37 layer around the particles, see main text) that is being burned during the TEM experiment.

The formation of monodisperse spherical AgNP was observed by both dynamic light scattering (DLS) and transmission electron microscopy (TEM; Fig. 1B). Note that the size measured by DLS, $19 \pm 1.0 \mathrm{~nm}$, was almost $14 \mathrm{~nm}$ larger than the observed in the TEM, which indicates the formation of a LL37 coating around the nanoparticle. Zeta potential measurements of LL37@AgNP revealed a positive potential of +37 $\pm 0.8 \mathrm{mV}$, in keeping with similar zeta potential values previously reported for other biomolecule capped AgNP.[11, 12] Only LL37@AgNP were stable up to 24 h in biocompatible buffers or cell 
culture media, unlike citrate@AgNP which was unstable (see Fig. S2) or AgNO3, which oxidized to silver oxide (data not shown).

Table 1. MIC values in $\mu$ M for total silver content measured in $25 \%$ LB at initial bacteria density of $\approx 1 \times 10^{5} \mathrm{cfu} / \mathrm{ml}$.

\begin{tabular}{|c|c|c|c|c|}
\hline & E. coli & P. aer. & S. epi. & S. aur. \\
\hline LL37@AgNP & 6.25 & 6.25 & 3.12 & 3.12 \\
\hline Citrate@AgNP & 6.25 & 6.25 & 6.25 & 6.25 \\
\hline AgNO3 & 3.12 & 3.12 & 3.12 & 3.12 \\
\hline AgSD & 3.12 & 3.12 & 3.12 & 3.12 \\
\hline
\end{tabular}

Table 1 shows that the minimal inhibitory concentration (MIC) for LL37@AgNP is similar to the control nanoparticles; citrate capped AgNP (citrate@AgNP), for Gram (-) $P$. aeruginosa and E.Coli. This is double the MIC for silver nitrate $\left(\mathrm{AgNO}_{3}\right)$ and silver sulfadiazine (AgSD). For Gram (+) S. epidermidis and $S$. aureus, however, the MIC was similar to $\mathrm{AgNO}_{3}$ and AgSD. In time kill experiments (Fig. 2), E. coli was considerably more susceptible to ionic silver, as previously reported in literature.[14] However, Fig. 2BD show that the bactericidal performance of LL37@AgNP was similar to that observed for $\mathrm{AgNO}_{3}$ against $P$. aeruginosa, $S$. epidermidis and $S$. aureus. No bactericidal effect of LL37 was observed for all the strains at similar concentrations $(<0.156 \mu \mathrm{M})$ to those in LL37@AgNP (see Fig. S3). All the anti-bacterial effects observed appeared to be conferred by AgNP.

As mentioned before, delayed wound healing is the main shortcoming of using ionic silver in infection prophylaxis.[2, 6, 7] We have previously shown that AgNP were more cell compatible than $\left.\mathrm{AgNO}_{3} .[11,12]\right\}$ Here, we show that our LL37 capped AgNP are not cytotoxic at the MIC or even at double the MIC, in contrast to the ionic silver (Fig. S4). In addition, LL37@AgNP did not hinder cell proliferation at double the MIC, unlike ionic silver, which showed inhibitory effects at half the concentration (Fig. 3A). Fig. S4 shows the cell viability measured after $14 \mathrm{~h}$ of incubation in the presence of different silver sources at 2X MIC for the opportunistic $P$. aeruginosa where they displayed bactericidal properties, see Fig. 2B. At such concentrations, it can be seen that $\mathrm{AgNO}_{3}$ and AgSD have between $60-40 \%$ of toxicity, under our experimental conditions, with a negligible toxicity for either LL37@AgNP or citrate@AgNP (control nanoparticles), see Fig. S4 ( $p>0.5$ ). Further, cell proliferation experiments up to seven days where the silver sources and the cell culture media were replaced every $48 \mathrm{~h}$, to somehow mimic sequential topical applications, showed that both ionic silver sources delayed the cell proliferation with a total toxicity after only day 3, as seen in Fig. 3A. A delay in cell proliferation was also observed for citrate@AgNP from day 5 onwards $(p<0.01)$ when compared to the control. However, with LL37@AgNP, there was no significant difference ( $>0.5)$ in cell proliferation from the controls without any added silver. Note that the cell proliferation values measured for 


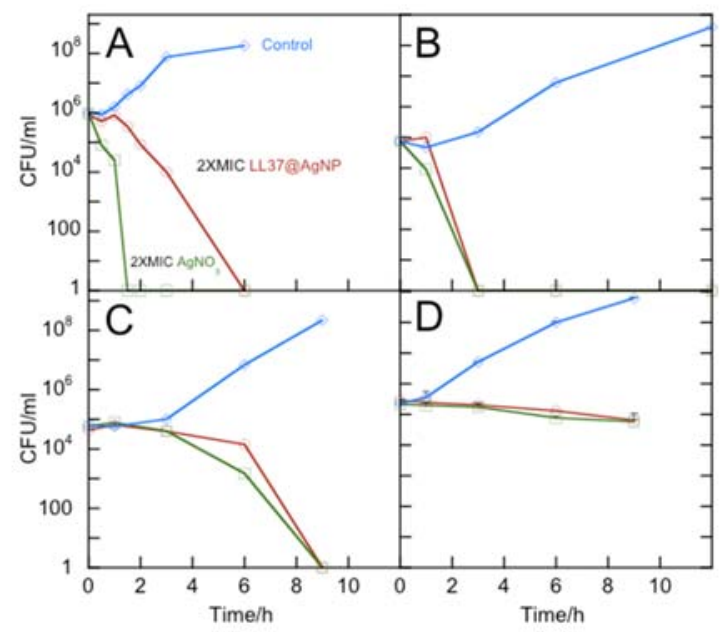

Figure 2. Number of survival bacteria colonies counted in the presence of $2 X M I C$, see Table 1 and main text, for AgNO3 () and LL37@AgNP (०) for (A) E. coli, (B) P. aeruginosa, (C) S. epidermidis, and (D) $S$. aureus. Control experiments where no silver was added are also included $(\diamond)$. All experiments were carried out in $25 \% \mathrm{LB}$ and colonies counted after $18 \mathrm{~h}$ of incubation at $37^{\circ} \mathrm{C}$ on agar plates.
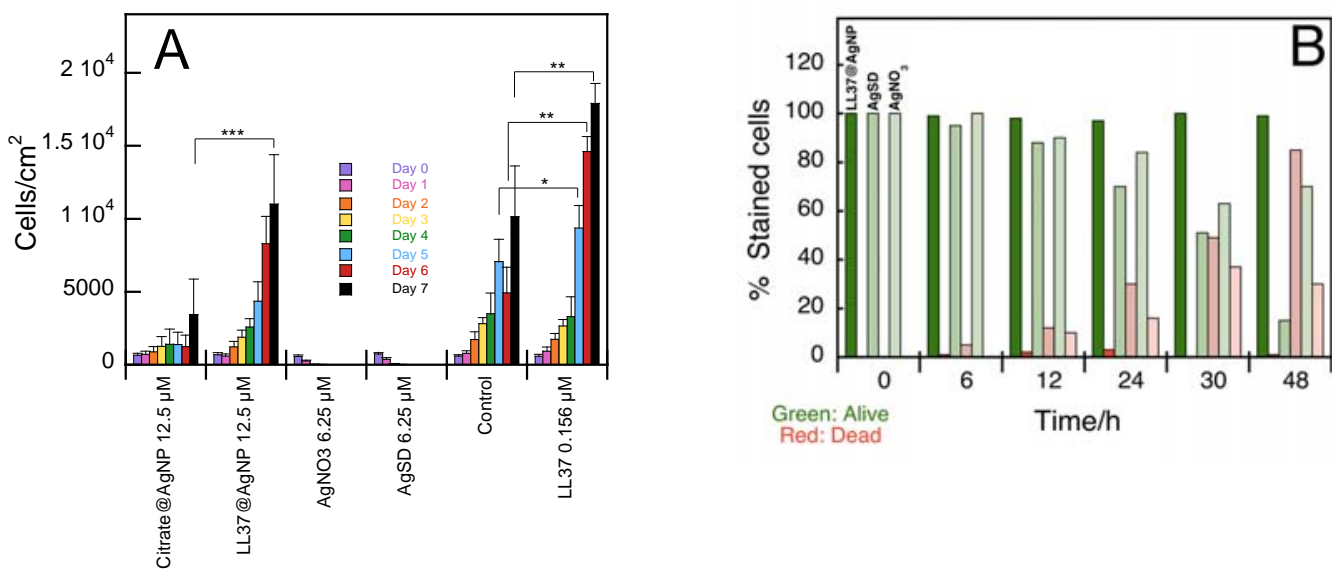

Figure 3. (A) Effect of silver nanoparticles or ionic silver on the proliferation profile of human skin fibroblasts. Silver source was changed every $48 \mathrm{~h}$ in fresh cell culture media. Error bars correspond to SD from six different samples obtained from triplicate experiments. T-Student two tail test, ${ }^{*} p<0.1,{ }^{* *} p<0.01,{ }^{* * *} p<0.001$. (B) Percentage of cells stained with AM-Calcein (green bars) or ethidium bromide homodimer (red bars) measured at different incubation times after the addition of $12.5 \mu \mathrm{M} L \mathrm{~L} 37 @ \mathrm{AgNP}$ or $6.25 \mu \mathrm{M} \mathrm{AgSD} / \mathrm{AgNO}_{3}$. Fluorescence emission was measured with a FTIC or long pass red filter, for green and red fluorescence respectively.

citrate@AgNP were considerably smaller than the measured at the same total silver concentration of LL37@AgNP, see Fig. 3A. These differences become much more important at 1XMIC of LL37@AgNP, see Fig. S5, where an increment in the cell proliferation from up to day $5(p<0.01)$ when compared to the control, was observed. In this study, the presence of LL37 promoted skin fibroblast proliferation by almost a factor of two after seven days $(p>0.5)$. Control experiments carried our for the ionic silver sources in the presence of LL37 show similar trends than those obtained when the peptide was not present (see Fig. S6). It has been reported that LL37 induces proliferation of some epithelial cells, including skin[15] and airway epithelial cells.[16] In this study, the stimulatory effect on skin fibroblast proliferation appears to be tempered when the peptide was conjugated to AgNP (Fig. 3A). Moreover, the antiproliferative effect of citrate@AgNP on skin fibroblasts shown in Fig. 3A, was observed only after continued exposure ( $>3$ days). This behavior points that the accumulation of toxic products, like AgO,[12] due to lack of stability of citrate@AgNP nanoparticles in the cell culture medium, see Fig. S2, is 
directly involved in the antiproliferative performance of citrate@AgNP. Further experiments carried out using Live/Dead ${ }^{\circledR}$ staining for up to $48 \mathrm{~h}$ in $6 \mathrm{~h}$ intervals, see Fig. $3 \mathrm{~B}$, shown that cell toxicity is observed within the first $24 \mathrm{~h}$ of incubation for $\mathrm{AgNO}_{3}$ and AgSD, with minimal toxicity for LL37@AgNP or citrate@AgNP (data not shown). Flow cytometry experiments using Alexa Fluor ${ }^{\circledR} 488$ Annexin and propidium iodide were also carried to detect signs of early apoptosis and necrosis, respectively.[17] The results presented in Table 2, see Fig. S7 for representative examples, show that the samples incubated with $\mathrm{AgNO}_{3}$ and AgSD for $12 \mathrm{~h}$ present a considerably higher necrotic population than either the control or those containing LL37@AgNP or citrate@AgNP which agrees with the observed in Live/Dead experiments, see Fig. 3B.

Table 2. Percentaget of survival, apoptotic and necrotic human skin fibroblasts cells evaluated using Alexa Fluor ${ }^{\mathrm{R}} 488$ Annexin and propidium iodide (see experimental) after $12 \mathrm{~h}$ of incubation with the different silver sources concentrations used in Fig. 3A. In all cases cell densities were kept in the same range than those employed in all the other cell viability experiments.

\begin{tabular}{c|ccc} 
Sample & $\begin{array}{c}\text { \% Viable } \\
\text { cells }\end{array}$ & \% Apoptotic & \% Necrotic \\
\hline Control $^{\dagger \dagger}$ & 95 & 1.0 & 4.0 \\
LL37@AgNP & 92 & 2.0 & 6.0 \\
Citrate@AgNP & 91 & 4.0 & 5.0 \\
AgSD $_{\text {AgNO }_{3}}$ & 76 & 6.0 & 18 \\
\hline
\end{tabular}

${ }^{\dagger}$ Percentages were calculated in Beckman-Coulter FC500 integrated software from the Propidium Iodide vs. Alexa Fluore 488 annexin plots. ${ }^{\dagger+}$ Control experiments were carried out by incubating the cells under the same conditions that the plates containing the silver sources in DMEM, 10\% FBS with no antibiotics.

LL37@AgNP are distinctly more biocompatible than citrate@AgNP (Fig. 3A) and are more stable (Fig. S2). In addition, the citrate@AgNP had a tendency to form a black precipitate, most likely AgO when prepared as a thin film at air-liquid interface.[12] This does not occur with LL37@AgNP. Thus, we also tested the capacity of LL37@AgNP to prevent the formation of $P$. aeruginosa biofilms using the liquid air interface (LAI) assay.[18] The results shown in Fig. 4 indicate that LL37@AgNP was able to prevent the formation of the Pseudomonas biofilm formation at both 1 and 2X MIC concentrations. In contrast, LL37 alone was not able to prevent biofilm formation even at twice the concentration present in 2XMIC, see Fig. 4.

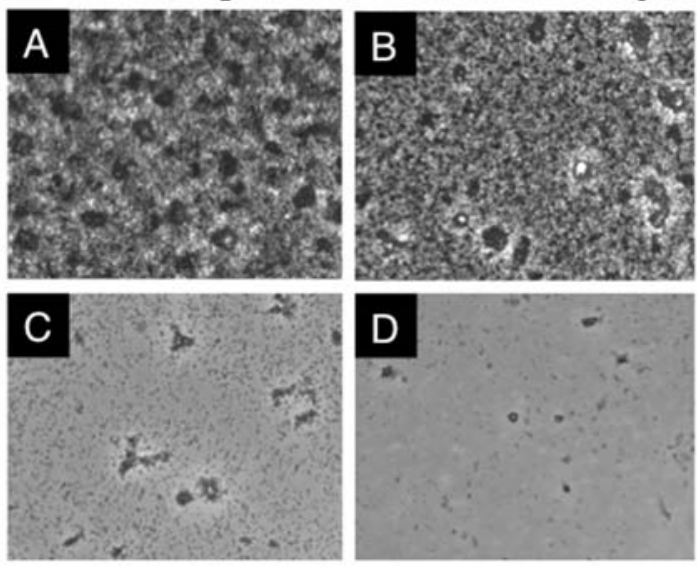

Figure 4. Bright field images showing A) $P$. aeruginosa biofilm that had formed on the surface of 6 well plates after $16 \mathrm{~h}$ incubation at $37^{\circ} \mathrm{C}$ without any anti-microbials (control); and $B$ ) biofilm formed in the presence of $0.156 \mu M$ LL37 peptide. In the presence of the minimal inhibitory concentration of LL37 coated AgNPs (LL37@AgNP),biofilm formation is dramatically reduced (C).At 2 XMICLL37@,AgNP, biofilm formation is minimal $(D)$. 
Although further testing of the material is still needed prior any clinical application, our cumulative data show that the side effects that silver application causes in the healing of skin wounds could be solved with the use of LL37 capped silver nanoparticles: LL37@AgNP, which provide the best of the two worlds; antibacterial properties against Gram positive and negative bacteria, and no anti-proliferative effect on primary skin cells.

\section{Conclusions}

The anti-proliferative or toxic effects of ionic silver and silver nanoparticles can be mitigated by the use of silver in form of peptide-stabilized nanoparticles. LL37 did not enhance the anti-microbial effect of the AgNP. Instead, the peptide had a stimulatory on the skin cells. As a composite, LL37@AgNP showed similar anti-microbial activity to clinically used ionic silver, but without the inhibitory effects on cell proliferation and with anti-biofilm activity, which is desirable in promoting wound healing while preventing potential infection in burn care.

\section{Acknowledgements}

We thank Dr. Klas Udekwu, Karolinska Institute for the bacterial strains. Support for this work is from a Collaborative Health Research Project grant (NSERC/CIHR Canada) to JCS, NSERC's CREATE program and Swedish Research Council grants to MG and JS.

\section{Notes and references}

1. Heath WR, Carbone FR. The skin-resident and migratory immune system in steady state and memory: innate lymphocytes, dendritic cells and $\mathrm{T}$ cells. Nat Immunol;14:978-985.

2. Church D, Elsayed S, Reid O, Winston B, Lindsay R. Burn wound infections. Clin Microbiol Rev 2006;19:403-434.

3. Steinstraesser L, Koehler T, Jacobsen F, Daigeler A, Goertz O, Langer S, et al. Host deferense peptides in wound healing. Mol Med 2008;14:528-537.

4. Duplantier AJ, van Hoek ML. The Human Cathelicidin Antimicrobial Peptide LL37 as a Potential Treatment for Polymicrobial Infected Wounds. Front Immunol 2013;4:1-14.

5. Humphreys G, Lee GL, Percival SL, McBain AJ. Combinatorial activities of ionic silver and sodium hexametaphosphate against microorganisms associated with chronic wounds. J Antimicrob Chemother 2011 August 25, 2011;66:2556-2561.

6. Aziz Z, Abu SF, Chong NJ. A systematic review of silver-containing dressings and topical silver agents (used with dressings) for burn wounds. Burns 2012;38:307318.

7. Klasen HJ. A historical review of the use of silver in the treatment of burns. II. Renewed interest for silver. Burns 2000;26:131-138.

8. Herzog F, Clift M, Piccapietra F, Behra R, Schmid O, Petri-Fink A, et al. Exposure of silver-nanoparticles and silver-ions to lung cells in vitro at the air-liquid interface. Part Fib Toxicol 2013;10:1-14. 
9. Naik RR, Jones SE, Murray CJ, McAuliffe JC, Vaia RA, Stone MO. Peptide Templates for Nanoparticle Synthesis Derived from Polymerase Chain Reaction-Driven Phage Display. Adv Funct Mat 2004;14:25-30;Clem Gruen L. Interaction of amino acids with silver(I) ions. Biochim Biophys Acta B 1975;386:270-274.

10. Nagant C, Pitts B, Nazmi K, Vandenbranden M, Bolscher JG, Stewart PS, et al. Identification of Peptides Derived from the Human Antimicrobial Peptide LL-37 Active against Biofilms Formed by Pseudomonas aeruginosa Using a Library of Truncated Fragments. Antimicrob Agents Chemother 2012;56:5698-5708.

11. Alarcon EI, Bueno-Alejo CJ, Noel CW, Stamplecoskie KG, Pacioni NL, Poblete H, et al. Human serum albumin as protecting agent of silver nanoparticles: role of the protein conformation and amine groups in the nanoparticle stabilization. J Nanopart Res 2013;15:1374-1377.

12. Alarcon EI, Udekwu K, Skog M, Pacioni NL, Stamplecoskie KG, Gonzalez-Bejar M, et al. The biocompatibility and antibacterial properties of collagen-stabilized, photochemically prepared silver nanoparticles. Biomaterials 2012;33:49474956.

13. Simpson MJ, Poblete H, Griffith M, Alarcon EI, Scaiano JC. Impact of dye-protein interaction and silver nanoparticles on rose Bengal photophysical behavior and protein photocrosslinking. Photochem Photobiol 2013;89:1433-1441.

14. Feng QL, Wu J, Chen GQ, Cui FZ, Kim TN, Kim JO. A mechanistic study of the antibacterial effect of silver ions on Escherichia coli and Staphylococcus aureus. J Biomed Mater Res 2000;52:662-668.

15. Heilborn JD, Nilsson MF, Kratz G, Weber G, Sorensen O, Borregaard N, et al. The Cathelicidin Anti-Microbial Peptide LL-37 is Involved in Re-Epithelialization of Human Skin Wounds and is Lacking in Chronic Ulcer Epithelium. J Investig Dermatol 2003;120:379-389.

16. Shaykhiev R, Beisswenger C, Kandler K, Senske J, Puchner A, Damm T, et al. Human endogenous antibiotic LL-37 stimulates airway epithelial cell proliferation and wound closure. Am J Physiol Lung Cell Mol Physiol 2005 200510-07 17:11:24;289:L842-L848.

17. Darzynkiewicz Z, Juan G, Li X, Gorczyca W, Murakami T, Traganos F. Cytometry in cell necrobiology: Analysis of apoptosis and accidental cell death (necrosis). Cytometry 1997;27:1-20.

18. Merritt JH, Kadouri DE, O'Toole GA. Growing and Analyzing Static Biofilms. Curr Prot Microbiol: John Wiley \& Sons, Inc., 2005. 